\title{
POST OCCLUSION HYPERTENSION AND PLASMA CATECHOLAMINE LEVELS ${ }^{1}$
}

A. W. Conn, M.D., B.SC.(MED), F.R.C.P. (C), ${ }^{2}$ and R. A. Mill IR, M.D., F.F.A.R.C.S. ${ }^{3}$

DERING HYPOTHERMIC anaesthesia for cardiovascular'surgery, it has been noted that a hypertensive phase follows the period of circulatory occlusion. The hypertension is of abrupt onset and of variable degree and duration. I ts characteristics have no obvious relationship to the type of cardiac lesion under repair, the presence or absence of vascular shunts, the duration of occlusion, or the degree of hypothermia. However, the hypertensive phase fails to occur when blood replacement is grossly inadequate or myocardial contractility is greatly diminished as with prolonged hypoxia, coronary air emboli and so forth.

Usually, there is a rise $\mathrm{in}_{11}$ the systolic and diastolic systemic pressures to approximately $160 / 110 \mathrm{~mm}$. Hg and sometimes to much higher levels. Simultaneous observation of the pulmonary arterial pressures reveals an insignificant rise $(<5 \mathrm{~mm} . \mathrm{Hg}$ ). With these considerations in mind it was decided to investigate the plasma catechol amine levels before and after the period of circulatory occlusion.

\section{METHOD}

Six children in good condition were selected (Table I). All had uncomplicated atrial septal defects of the secundum type which were repaiced under direct vision during a period of circulatory occlusion: Hypothermic anaesthesia was conducted according to techniques previously outlined (1.). The systemic blood pressure was monitored using a Collens oscillometer and an intra-arterial needle connected to a transducer and a Sanborn (150 M. series) six-channel recorder. Samples of blood (50 cc.) were withdrawn from the femoral artery with simultaneous intravenous blood replacement. Two samples were taken preceding the

TABLE I

\begin{tabular}{|c|c|c|c|c|c|c|c|c|}
\hline \multirow[b]{2}{*}{ Patient } & \multirow[b]{2}{*}{$\operatorname{sex}$} & \multirow{2}{*}{$\begin{array}{l}\text { Age } \\
\text { (1rs) }\end{array}$} & \multirow{2}{*}{$\begin{array}{l}\text { Meight } \\
\text { (in lba) }\end{array}$} & \multicolumn{2}{|c|}{ Occlusion temperature } & \multirow{2}{*}{$\begin{array}{l}\text { Duration } \\
\text { of occlusion } \\
\text { (in nuin.) }\end{array}$} & \multicolumn{2}{|c|}{ B.P. increase } \\
\hline & & & & Esophageal & Rectal & & Systolic & Diastolic \\
\hline 1 & $M$ & $\dot{G}$ & 321 & $20: 3$ & 295 & 4 & 50 & 30 \\
\hline 2 & $F$ & 6 & $+11^{\circ}$ & 242 & 30.2 & 3.5 & 80 & 60 \\
\hline 3 & $\mathrm{~F}$ & 8 & 39 & 293 & 290 & 35 & 100 & 60 \\
\hline 4 & $\mathrm{~F}$ & $\frac{1}{3}$ & $55 \frac{1}{2}$ & 300 & 310 & 30 & 50 & 40 \\
\hline 5 & $\mathrm{~F}$ & 12 & 64 & 305 & 311 & 4.0 & 100 & 35 \\
\hline 6 & $\mathrm{~F}$ & 7 & 37 & 317 & 312 & 5 & 55 & 40 \\
\hline
\end{tabular}

IFrom the Research Institute, Hospital for Sick Children, Toronto, Canada.

${ }^{2}$ Department of Anaesthesia, Hospital for Sick Children and University of Toronto.

${ }^{3}$ Department of Anaesthesia, Montreal Neurological Institute and McGill Iniversity. 


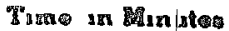

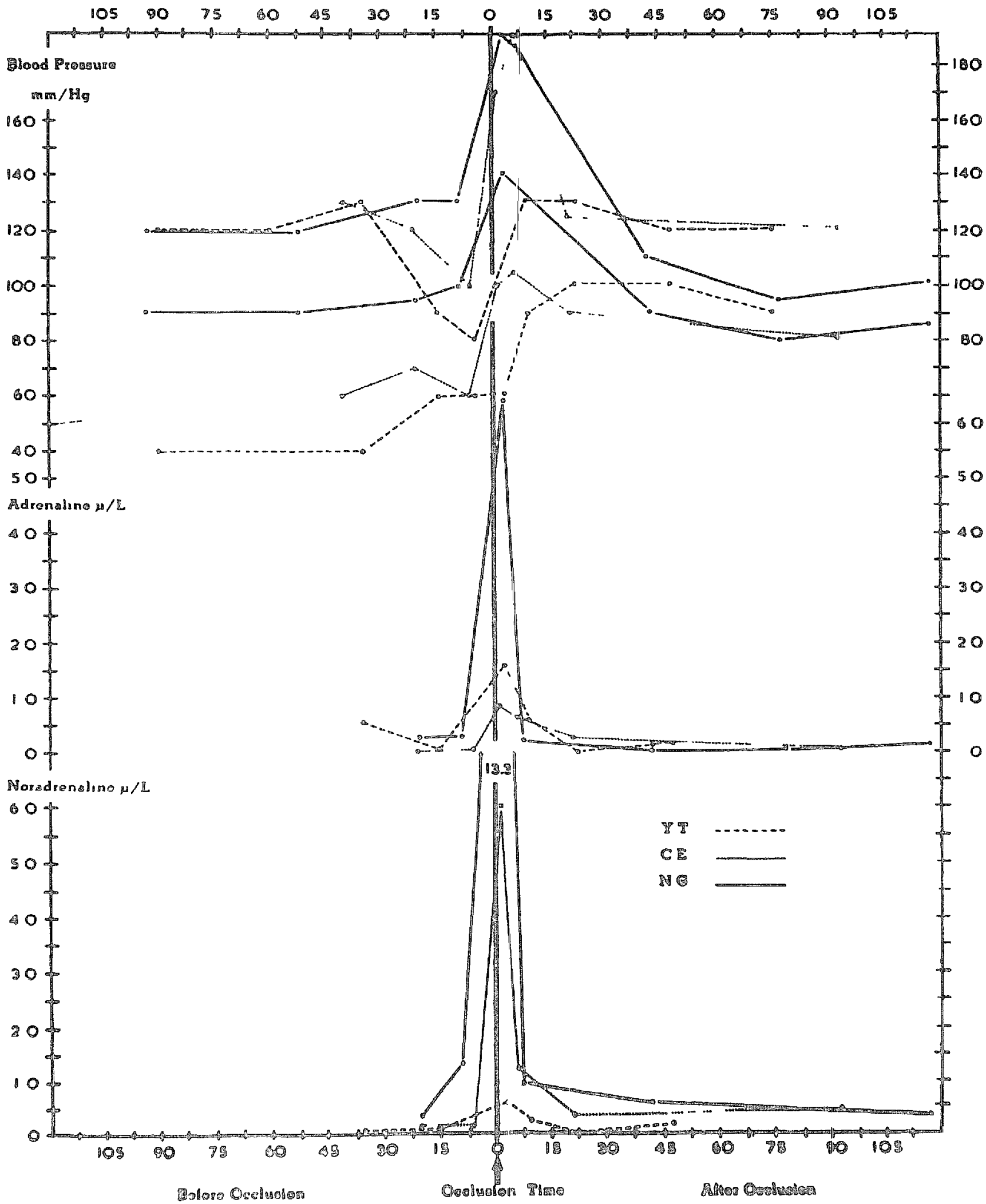

FIGL'RE 1 


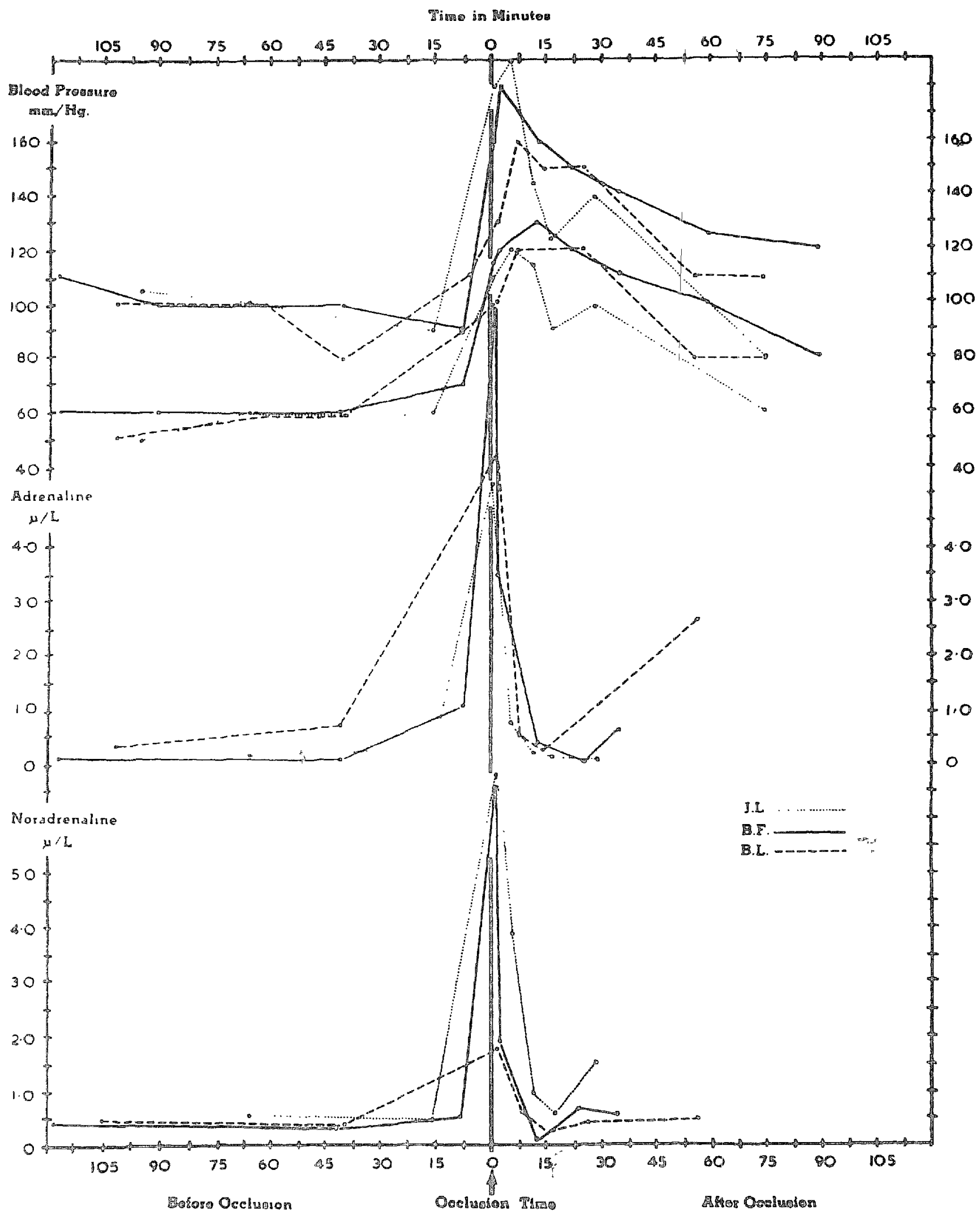

Figure 2 
period of occlusion as controls, and the remainder were taken during the hypertensive phase. These samples were analysed by one of us (R. A. M.) using a method recently described (2).

\section{RESULTS}

The results are illustrated in Figures 1 and 2 and are self-explanatory. The obvious relationship between the sudden increase in systemic blood pressure and the abrupt rise in plasma adrenalin and noradrenalin is apparent. Such high levels have only been encountered before in man in cases of phaeochromocytoma, although such levels are seen during haemorrhage and severe respiratory acidosis in dogs. Hypoxia is probably the major stimulus to release of these substances, but the exact mode of the stimulation and additional factors responsible remain to be investigated.

\section{STMMARY}

During hypothermic anaesthesia for cardiovascular surgery, it has been noted that a hypertensive phase immediately succeeds the period of circulatory occlusion. The mechanism of the hypertension was investigated in six patients by determining the adrenalin and noradrenalin plasma levels before and after occlusion. A close relationship was observed between the sudden increase in systemic blood pressure and the abrupt rise in plasma catechol amines.

\section{RÉSCMÉ}

Nous avons remarqué que l'occlusion circulatoirre était suivie d'une periode d'hypertension dans nos cas d'hypothermie pour chirurgie cardiovasculaire. Nons avons recherché la concentration d'adrenaline et de noradrenaline plasmatique, avant et apris occlusion chez ces patients. Les résultats ont confirmé qu'il y avait une intime relation entre l'augmentation de pression artérielle et le taux des catecholamines dans le plasma.

\section{REFERENCES}

1. Coxw, A. W., Allax, D., \& Junkr, C. I. Anaesthesia With Hypothermia For Closure of Atrial Septal Defects in Children. Canad. Anaesth. Soc. J. 6:327-335 (1959).

2. Millar, R. A., \& Bexfey, B. G. The Fluorimetric Estimation of Adrenaline and Noradrenaline during Haemorrhagic Hypotension. Brit. J. Anaesth. 80 : 158-165 (1958). 